\title{
Documenting horizons of interpretation in philosophy
}

\section{Ernesto Priani Saisó}

History of Philosophy and Humanities Computing, Facultad de

Filosofía y Letras, Universidad Nacional Autónoma de México

Leticia Flores Farfán

History of Philosophy, Facultad de Filosofía y Letras, Universidad

Nacional Autónoma de México

Isabel Galina

Instituto de Investigaciones Bibliográficas, Universidad Nacional

Autónoma de México

Rafael Choreño Gómez

History of Philosophy, Facultad de Filosofía y Letras, Universidad

Nacional Autónoma de México

Marat Ocampo Gutiérrez de Velasco

Facultad de Filosofía y Letras, Universidad Nacional Autónoma de México

Correspondence:

Ernesto Priani Saisó, History

of Philosophy and

Humanities Computing,

Facultad de Filosofía y

Letras, Universidad Nacional

Autónoma de México,

Circuito Interior Ciudad

Universitaria s/n, 04510,

México D.F. Email:

epriani@gmail.com

\section{Abstract}

Estrategias Contemporáneas de Lectura is a project focused on research and teaching that emphasizes the importance of interpretation in the study of Classical Antiquity. The aim of the project is to support research with digital tools that document the process by which a perspective point or horizon of interpretation is constructed, by following the development of individual and group work processes. The progress of the project has posed theoretical and technical challenges related to a diversity of methodologies and expectations of the project. However, the development of these discussions has showed the relevance of interpretation and its complexity, making it a fruitful experience.

\section{Introduction}

There is consensus regarding the importance of interpretation in the study of Greek and Roman Antiquity. Interpretation is not only a process, but a construction that establishes a perspective of understanding. Gadamer notes that 'The task of historical understanding also involves acquiring an appropriate historical horizon, so that what we are trying to understand can be seen in its true 
dimensions' (Gadamer, 2004). Thus, the act of interpretation is understood as intentional and also determined by an acquired perspective point or Horizon. Gadamer argues that prejudices need to be considered as the backbone of understanding. The importance of philosophical work is to make them conscious rather than being determined by them.

We propose that interpretation is not only intentional, but also an act of power. Althusser (1970) argues that the way in which we interpret, builds up truth: 'The sighting is thus no longer the act of an individual subject, endowed with the faculty of "vision" which he exercises either attentively or distractedly; the sighting is the act of its structural conditions, it is the relation of immanent reflection between the field of the problematic and its objects and its problems'. The construction of interpretation has a political perspective that not only wants to state truth, but to establish it. The risk, and relevance of studying interpretation is to keep it on the verge of truthfulness, instead of the establishment of truth.

In 1990, Barbara Cassin organized the series of conferences Les Stratégies contemporaines d'appropriation de l'Antiquité (Cassin, 1992) where a group of researchers working with different perspectives on the appropriation of Antiquity, recognized the important role of interpretation in this process. Their objective was not to explore Antiquity, but rather to pinpoint the framework that different authors constructed as they explored antique materials.

The implications of these series of conferences led a group of professors and researchers at the Facultad de Filosofía y Letras (Faculty of Philosophy and Literature) at the Universidad Nacional Autónoma de México (UNAM) to explore ways to study and teach contemporary strategies of appropriation of Antiquity. The main hypothesis of the project was that we cannot have access to Classic Antiquity without mediation or heritage and we should work and teach considering this perspective. Reading and studying Classical Philosophy involves taking position on a horizon, from which the object of research is built, related problems are stated, and the focus point is chosen.
Initially, the main objective of the project was to establish a seminar and produce academic papers on Contemporary Strategies of Appropriation of the Antiquity. These materials would be edited and published in a series of digital and printed materials to be used as teaching resources in several courses in Contemporary and Classical Philosophy at the Faculty. The findings would be used to teach the conceptions of contemporary authors and their ideas of Classical philosophy and to explain technically to students the processes that produce an interpretation.

\section{Toward a digital approach}

The first consideration of the project was to publish and print the work done in a seminar, but as the project developed, the possibility of using digital tools showed relevant advantages. The idea of using web-based technologies for a collaborative documentation project came afterwards, once the theoretical perspective about the project was settled. The project's approach to the problem created a paradox: in order to describe the horizons of interpretation of the authors discussed, both, individually and as a group, we needed to identify our horizons. So, we asked ourselves, how can we document this process? And with this documentation, how can we describe the horizons from which they are writing? And, could we use the documentation for teaching?

Differentiating our study from traditional research in philosophy, which analyzes the horizon of interpretation from a finished paper, we wanted to produce a record of ongoing work to show how the horizons are created and how they change in the process, with the influence of new readings, the interaction with other researchers, and other sources that modify the horizon of understanding. These goals lead us to consider two main problems:

(a) What kind of data did we need to collect to have an idea of the horizon of interpretation?

(b) How to collect data in an open and dynamic way that would allow us to follow the process of research and its changes during a period of time? 
In order to do so we focused on two activities in academic literacy: reading and writing. The kinds of data we wanted to obtain were the reading annotations as an evidence of the reading process and the development of writing (Geisler, 1994). Also, it was relevant for us to keep record of the individual researching methodologies not only as a definitive perspective but also as a succession of variations. All these data would be obtained while researchers are working on the project and until they finish their papers. It was vital to have not only a record of individual activity but also of the collective work of the professors.

\section{Blogging, annotating, writing}

Our solution (Fig. 1) is based on an application of collaborative 'crowdsourcing' (Albors, 2008), following previous experiences in Digital Humanities. For instance, we considered the success of 'A Day in the Life of Digital Humanities', using blogging and wiki for collaborative documentation of daily activities of digital humanists. ${ }^{1}$

The project, Estrategias Contemporáneas de Lectura, consists of twenty-five researchers writing their own blogs (Fig. 3) in which they document their daily research activities, as well as comment other blog entries during a period of 1 year. This mechanism allows us to have a virtual interaction of researchers and to trace collective work around independent participation. Additionally, we are collecting annotations and methodological assumptions. In order to do so, we developed a web application for these specific needs. The web application was developed in house using Extensible Markup Language (XML) and open-source blogging software. The application has two main tools, one for capturing and highlighting quotes and other for explaining and updating methodology.

\subsection{Capturing and highlighting quotes}

The web application allows researchers to upload book passages (Fig. 4) and highlight paragraphs in order to document and share their readings. Every passage is open to be marked by different researchers and the web application allows comparisons between these marks. Highlighting different parts of a same text shows individual decision and collective results.

During the project, all the markup will be referenced to a location on the passage and they will be rendered with Javascript. This lets the marks be collected outside the working material. Once the project is finished, the marks will be exported to TEI to preserve the documents and marks that will be part of the text. Nevertheless, during the process participants can mark dates, names, terms, and quotes as done with TEI Lite (cf. Burnard, 2006) in order to also produce such a markup of the text that is didactically useful, for example, by linking those marks to complementary information about referenced names, terms used, etc. Passages entries and highlighted material can be commented by other participants and linked to blog entries.

\subsection{Explaining and updating methodology}

Researchers can explain their methodology and are able to update their methodological assumptions anytime they decide to change the study methodology or subject in our web application, simply by filling the methodology box in their profile. At the end of the project, we will be able to compare the evolution of the research in a timeline, mixed with their blog post and annotation, having an insightful way to analyze the initial work and their finished paper.

\section{Individual and collective material}

Highlighting quotations and comments on blog and quotation entries are ways to have evidence of individual decisions and collective assumptions. We use this process to create metadata from the results of the combination of individual work. As it is used in many commercial and academic projects, researchers can create metadata or use those that had been created by others, for sources excerpts and blogs. Metadata is central to finding links between autonomous and collective work. The finalized project can help us to understand how 
collective or the individual views interact, finding parallel or intersecting material. We are currently working on the metadata creation rules.

\section{The didactic aim}

As an educational project, another objective is to use the documentation to help students to understand how we study Classical Antiquity from a horizon of interpretation. As a tool for education, it allows students to: (a) Follow individual researcher's work in real time during the activity of the project.

(b) Compare quotes and highlighted material used by different researchers.

(c) Follow the entries (blogging, passages, highlighting, methodology) on a modern or classical author.

(d) Check additional information about modern or classical authors (Fig. 2) (reference, biography, bibliography).

\section{Figures}

\subsection{Workflow}

\section{Documenting horizons of interpretation in philosophy} Workflow

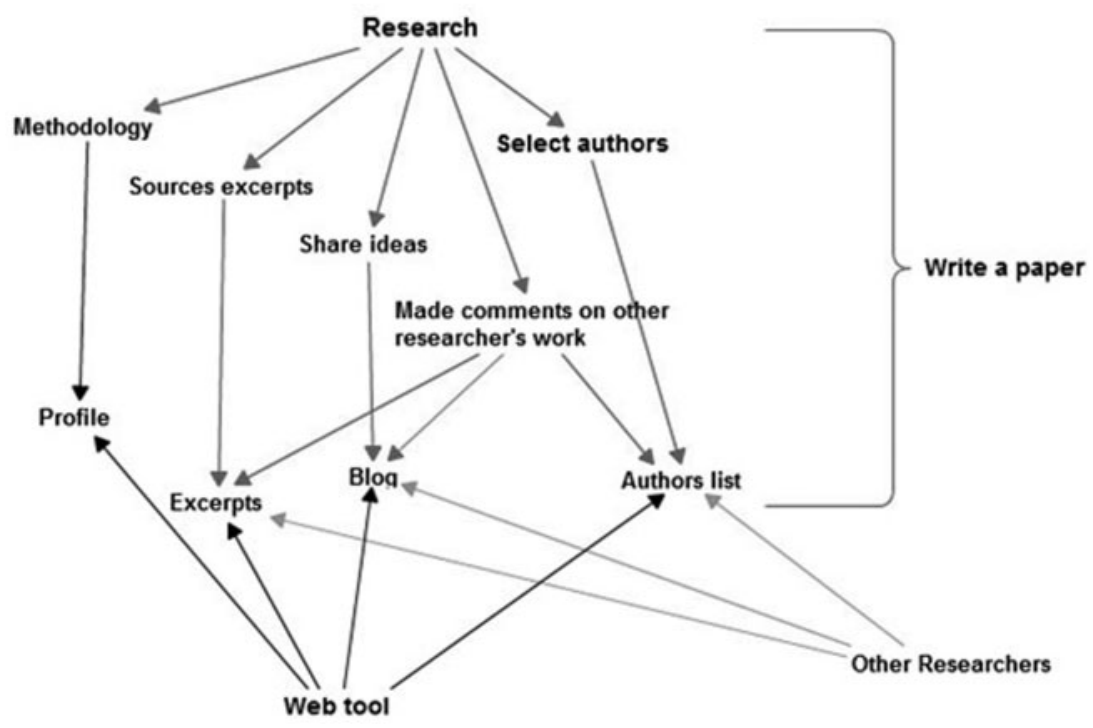

Fig. 1 Shows the workflow process for the project. It considers the interaction between the researchers' perspective and the web tool elements. 


\subsection{Authors}

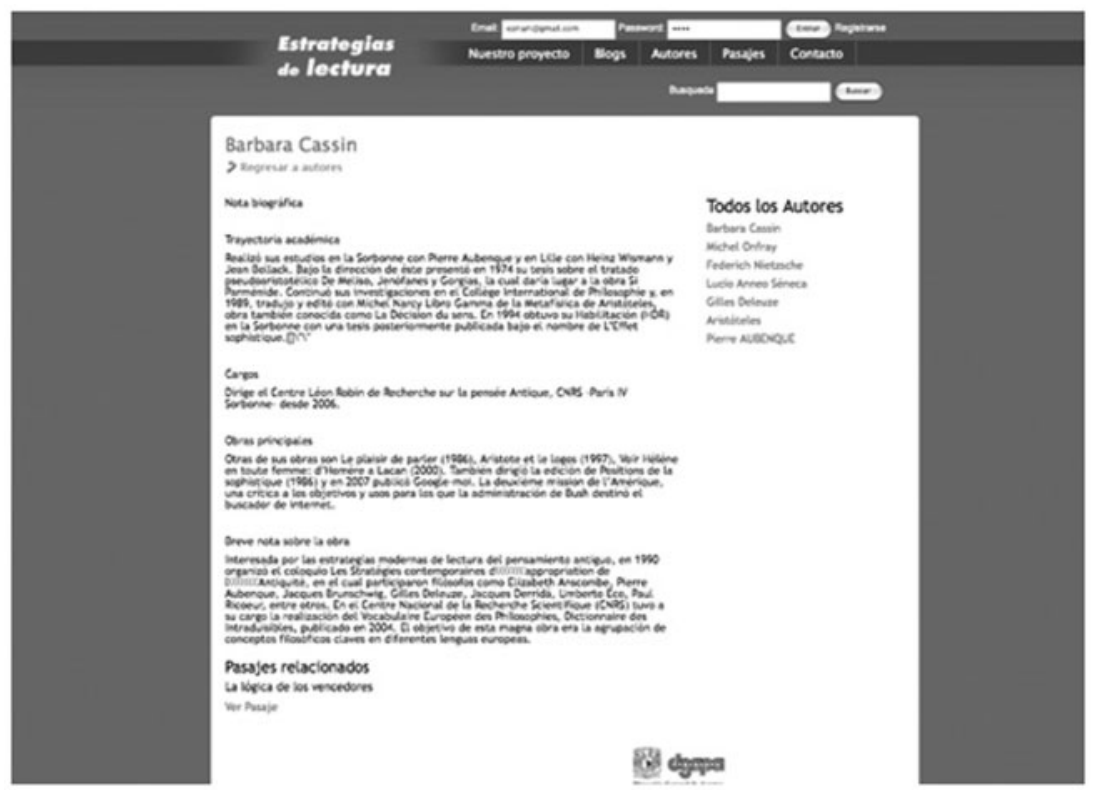

Fig. 2 Screenshot showing the main interface of the Author tool. There is also a link to related material in the blogs to this author.

\subsection{Blog}

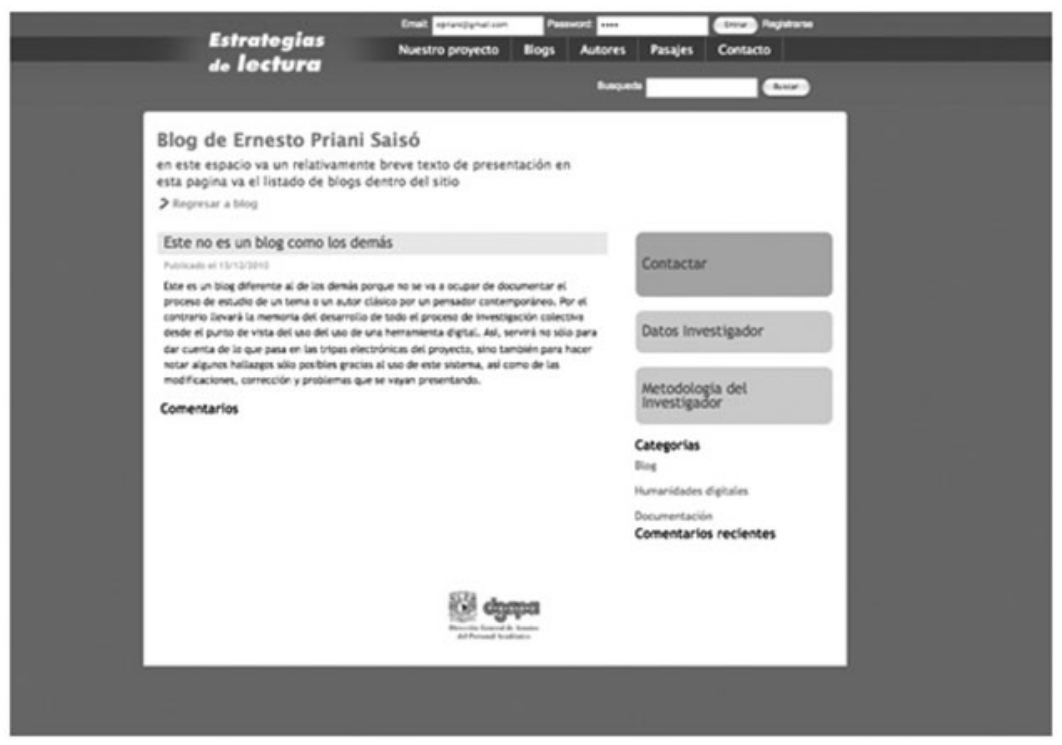

Fig. 3 Screenshot of a blog entry. 


\subsection{Source excerpts}

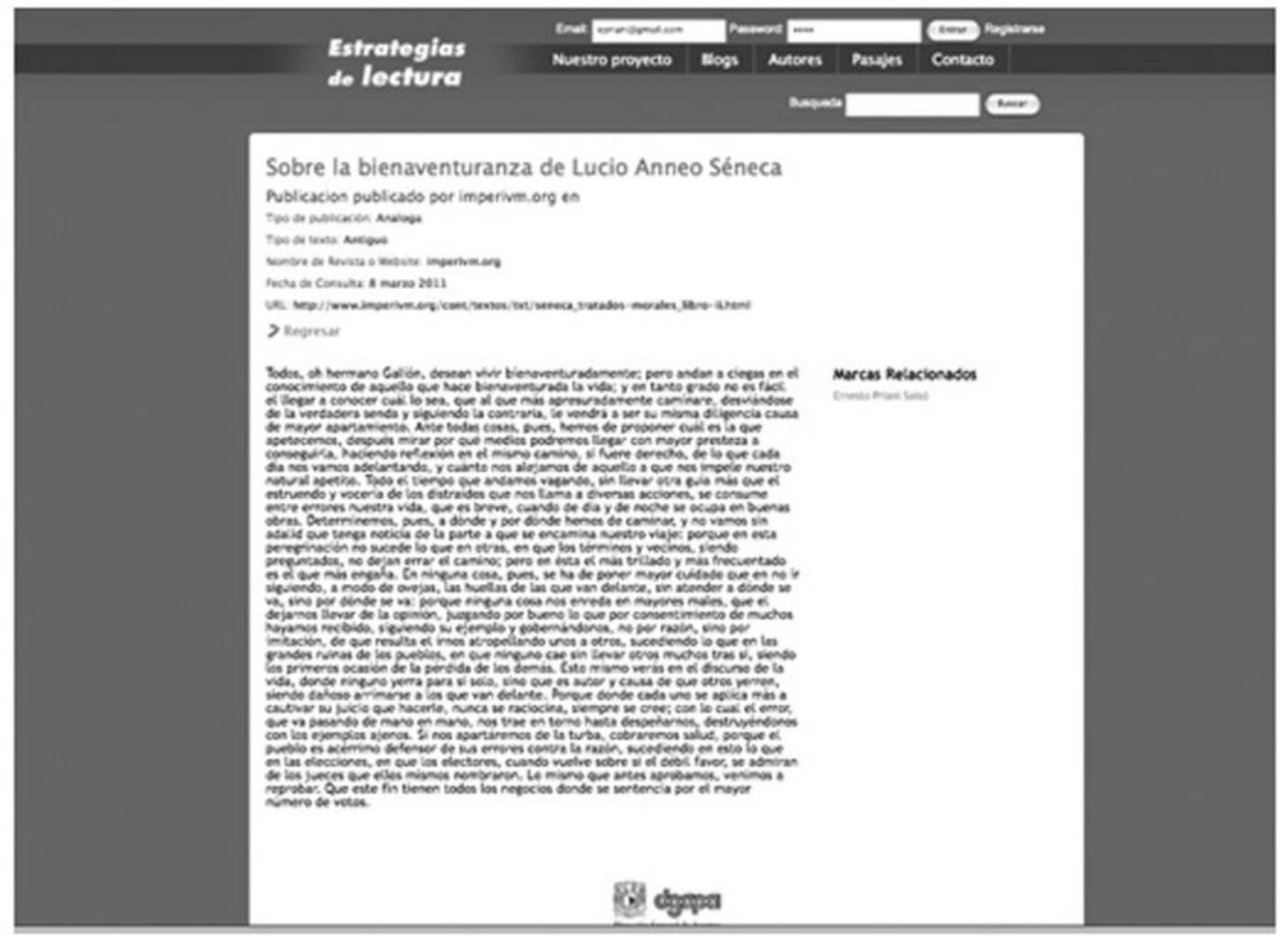

Fig. 4 The Passage tool shows a fragment of one of the captured study texts.

\section{Discussion}

So far, the project has been used in a sandbox environment for a test group. Twelve users registered and have been using the Blog, Passage and Author tools for the last 8 months. The users stated a methodology, as well as an investigator profile. Site traffic is limited and we are still having issues with methodology and site administration. There are problems related to technical issues, collaboration, training, structure, and the boundaries between informal online styles and formal academic work.

The authors encountered some technical issues that delayed the project. Although these are now solved, some users started working offline and so part of this interaction is now lost. We need to consider the deviation it will cause in the data collected, or how to integrate this experience. Some format issues are still outstanding, including incorporating particularities of working styles to quote and add material as blog items.

Some users found difficulties in the structure of the web page and user training will be addressed shortly. Additionally, we have not made use of the more advanced features of marking and tagging material in each passage. The Passage tools are specific to the project and require some training to use them. A group is being formed to help guide users to make the most of the tools. The debate continues as we ask ourselves: what do we want to tag? What do we want to standardize? These 
aspects need to be addressed in order to help users learn how to use the site.

Concerns regarding the distance created by web-based work were raised, arguing that the interaction between users is important. There has been little interaction between authors using the blogs. This has led the project to work more like an independent collection of blogs rather than a group effort. Additionally, the Passage tool is underused. While the number of passages has grown day by day, the lack of interaction has made them just quotations. There are few comments and less feedback of those comments.

Some of the participants participate in a seminar that works as a discussion forum for theoretical and technical aspects. This way the initial perspective that considered seminar work has been reincorporated into the process. The difference between the digital tool and the seminar is that the tool incorporates the progress of the investigation, while the seminar works as a support for the communitarian intentions of the project overcoming the distance and separation inherent to the remote participation. The main issue regarding this process is not to underestimate the possibility of collective work online and build a community.

There are ongoing discussions in relation to reading strategies. We have identified differences in the classification of authors; those from Antiquity, those whose horizon of interpretation is considered, and the rest of support literature. This has led to a debate on the different types of authors interpreting Antiquity and the relative importance of each one. The complexity of understanding a strategy of interpretation is surfacing.

The experience has been rewarding with regards to the difficulties of differentiating working with the drafts of the final product and documenting the process. Working with drafts can be part of the process but it is not documenting the process itself. We have ongoing discussions on different approaches to this problem; some that grant the draft approach the value of documentation and others that argue that this would leave lots of important elements out, lessening the value as a pedagogic tool.

\section{Conclusions}

The project is still in development status. The group needs to study how to establish more specific site rules and academic practices to manage the material. We are currently collecting feedback in order to improve site navigation and tools. We are also incorporating new users successfully. We are now in the transition where the test group becomes the actual working group incorporating the complete community of researchers. The aim of this second phase will be to develop the quality standards for the material and emphasize the relevance of different approaches.

The Project will be delivering its initial results in November 2011, with a significant number of researchers participating using the system. This will give us the scope of subjects and perspectives that are being studied. We hope that this will open up the project to be followed by students and to participate in the exchange of comments and material through the web. We also want to find the balance between the seminar sessions and web work to develop both direct and remote participation that delivers group results.

We calculate that the project requires at least a year to harvest significant results. We are working toward developing a structure that will make this tool a model for online collaborative work in the Philosophy faculty with pedagogic aims. Moreover, we think that the results concerning the debate surrounding interpretations will help to bring new elements into teaching Ancient Philosophy and Hermeneutics.

\section{References}

Albors, J., Ramos, J. C., and Hervas, J. L. (2008). New learning network paradigms: communities of objectives, crowdsourcing, wikis and open source. International Journal of Information Management, 28: 194-202.

Althusser, L. and Balibar, É. (1970). Reading Capital [Tr. Ben Brewster]. London: New Left Books.

Cassin, B. (1992). Nos Grecs et leurs moderns. Les Stratégies contemporaines d'appropriation de l'Antiquité. Paris: Editions du Seuil. 
Gadamer, H. (2004). Truth and Method [Tr. Joel Weinsheimer and Donald G. Marshall]. New York: Continuum.

Geisler, C. (1994). Academic Literacy and the Nature of Expertise: Reading, Writing, and Knowing in Academic Philosophy. New Jersey: Lawrence Erlbaum Associates, p. 15.

\section{Note}

1 Day in the Life of the Digital Humanities project is available at: http://tapor.ualberta.ca/taporwiki/index .php/Day_in_the_Life_of_the_Digital_Humanities_ 2010 (accessed 5 October 2012). 